\title{
Comparison of risk factors, severity and outcome between lacunar and non-lacunar stroke in a tertiary care center in Sri Lanka: A descriptive study
}

\author{
N D Perera, K M Bandara, I R Ranasinghe, S B Gunatilake \\ (Index words: lacunar, non-lacunar, stroke, risk factors, Ischaemic stroke, stroke subtypes)
}

\begin{abstract}
This study compares demography, risk factors and outcome of lacunar (LAC) and non-lacunar (non-LAC) strokes from the prospective hospital based stroke registry at Colombo South Teaching Hospital from $1^{\text {st }}$ March 2012 to $30^{\text {th }}$ June 2013. Data on admission, discharge and at 28 days after discharge were analysed. There were 229 ischaemic stroke (IS) patients. Average age was 65.7 years (SD 12.2, range 34-94) and 116 $(50.7 \%)$ were males. LAC $(n=130,56.8 \%)$ were common than non-LAC ( $\mathrm{n}=99,43.2 \%)$. There were $75(64.7 \%)$ males and $55(48.7 \%)$ females in the LAC group (adjusted OR 2.1, 95\% Cl 1.08-4.29). Atrial fibrillation was less frequent among LAC stroke (OR 0.3, 95\% Cl 0.09-0.99). Hypertension, diabetes, smoking, dyslipidaemia did not differ in the two groups. Lower NIHSS (5.34 Vs 6.6, $p=0.053)$, higher GCS (14.7 Vs 13.3, $p=0.001$ ) were seen in LAC. Disability (MRS, Barthel index) on discharge, at 28 days and mortality during hospital stay and within 28 days was lower in the LAC group $(p<0.001)$.
\end{abstract}

Ceylon Medical Journal 2015; 60: 103-106

\section{Introduction}

Prevalence of stroke is rising worldwide and is particularly common in South East Asia [1]. It is the fourth commonest cause for in-hospital mortality in Sri Lanka [2]. Available studies on prevalence of stroke in Sri Lanka show a community prevalence of $1.6 \%$ [3].

Different classification systems have emerged and the division into lacunar (LAC) and non-lacunar (nonLAC) subtypes were proposed with the intent of identifying different pathogenic and risk factor profiles. First such information was provided by Fisher fifty years ago, based on autopsy findings [4]. He proposed that lacunar strokes, asymptomatic small infarcts in striatocapsule are due to small vessel disease in the penetrating arteries and was the result of lipohyalinosis or atherosclerosis. Thus emerged the 'lacunar hypothesis' and these findings have led to studies on the two subtypes of stroke further enumerating that hypertension, diabetes and hyperlipidaemia are common in lacunar stroke with cardio embolism and large artery disease deemed less important [1,5]. But recent studies show that the risk factor profile is not different in stroke subtypes questioning the validity of lacunar hypothesis [6-8]. Further data suggest that genetic predisposition might influence the type of stroke in patients with similar vascular risk factors [9].

LAC are commoner in Asians and Japan reports a 50$60 \%$ incidence among ischaemic strokes compared to $16-$ $38 \%$ in European and North American populations [1,13]. Reasons for this difference is not clear and the pattern in Sri Lanka is not known. There is only one study on stroke subtypes from Sri Lanka [10]. This study showed a LAC occurrence of $41 \%$ among ischaemic stroke. Studies show that the early death rate as well as the risk of recurrence and disability are higher in non-lacunar strokes than lacunar strokes [5,8,11].

Aim of our study was to compare the risk factors, demographic factors and the outcome in lacunar and nonlacunar stroke patients admitted to Colombo South Teaching Hospital.

\section{Methods}

We recruited all ischaemic stroke patients from the stroke registry at Colombo South Teaching Hospital from the $01^{\text {st }}$ March 2012 to $30^{\text {th }}$ June 2013. This registry established in 2012 includes all stroke admissions to medical wards in the hospital. All patients had neuro imaging (CT brain). Stroke subtype was determined according to the TOAST classification [12]. These patients were further subdivided to lacunar and nonlacunar stroke by the treating physician depending on the imaging findings and clinical presentation. LAC was assigned if the following criteria were met: a) estimated

Department of Medicine, University of Sri Jayewardenepura, Sri Lanka.

Correspondence: SBG, e-mail: <saman.gunatilake@hotmail.com>. Received 28 April and revised version accepted 4 July 2015. 
infarct size $\leq 2 \mathrm{~cm}$, b) anatomic site typical of LAC (basal ganglia, brainstem, thalamus, internal capsule or cerebral white matter) and c) compatible clinical presentation [1].

All patients were interviewed and examined to assess the severity of stroke using National Institute of Health Stroke Scale (NIHSS). Glasgow coma scale (GCS) was adopted if NIHSS could not be used due to reduced level of consciousness. Demographic factors, smoking history, history or a new diagnosis of DM, HT, ischaemic heart disease, atrial fibrillation and dyslipidaemia were documented. Modified Rankin scale (MRS) and the Barthel index were assessed on discharge as a measure of residual disability. Death during hospital stay was noted. These patients were re-assessed at 28 days to document MRS, Barthel index, occurrence of re-infarction and hospitalisation during follow up. There were 22 dropouts at one month at a rate of $9.6 \%$.

Data were entered and analysed using SPSS version 19.0. Descriptive data were described using frequencies, means and standard deviations. Logistic regression was used to find the association between vascular risk factors and stroke subtype. Multivariate analysis was used to eliminate the effect of confounding variables. Association between mean NIHSS, MRS, Barthel index and stroke subtype was assessed using t-test. Chi-square test was adopted to find the association between death, stroke recurrence and stroke subtype.

Informed consent was obtained from all participants. Ethical approval was obtained from the Ethics Review Committee of Faculty of Medical Sciences, University of Sri Jayewardenepura.

\section{Results}

Two hundred and twenty nine IS patients were studied. Average age was 65.7 years (SD 12.2, range 34-94). There were 116 (50.7\%) males and 113 (49.3\%) females (Table 1). Commonest stroke subtype was stroke due to small artery occlusion $(n=127,55.5 \%)$. Others were stroke due to large artery atherosclerosis $(n=79,34.5 \%)$, cardio embolism $(n=15,6.6 \%)$ and undetermined aetiology $(n=8,3.5 \%)$. LAC stroke $(n=130$, $56.8 \%$ ) was more than non-LAC stroke ( $n=99,43.2 \%)$.

The association of risk factors with LAC and nonLAC is shown in table 2. LAC stroke was significantly more in males. Dyslipidaemia was commoner in LAC than non-LAC stroke on univariate analysis but became nonsignificant when adjusted for confounding factors (Table 2). Presence of HT, DM, smoking or past TIA/ stroke did not differ in LAC and non-LAC groups. Atrial

Table 1. Patient characteristics, presence of vascular risk factors and stroke type in males and females

\begin{tabular}{|c|c|c|c|c|}
\hline Patient characteristic & $\begin{array}{c}\text { Males } \\
\text { Total }=116 \\
n(\%)\end{array}$ & $\begin{array}{c}\text { Females } \\
\text { Total }=113 \\
n(\%)\end{array}$ & $\begin{array}{c}\text { Total } \\
\text { Total }=229 \\
n(\%)\end{array}$ & $p$ values \\
\hline Age mean (SD) & $\begin{array}{c}63.69 \\
(12.07)\end{array}$ & $\begin{array}{c}67.68 \\
(12.15)\end{array}$ & $\begin{array}{c}65.7 \\
(12.2)\end{array}$ & $p=0.016$ \\
\hline \multicolumn{5}{|l|}{ Time to hospital admission } \\
\hline $\begin{array}{l}\leq 4.5 \text { hrs } \\
>4.5 \text { hrs } \\
\text { Systolic BP mean (SD) } \\
\text { Diastolic BP mean (SD) }\end{array}$ & $\begin{array}{c}34(29.3) \\
82(70.7) \\
149.9(24.3) \\
86.36(14.7)\end{array}$ & $\begin{array}{c}33(29.2) \\
80(70.8) \\
152.4(26.7) \\
84.45(15.8)\end{array}$ & $\begin{array}{c}67(29.2) \\
162(70.7) \\
151.2(25.5) \\
85.4(15.3)\end{array}$ & $\begin{array}{l}p=0.98 \\
p=0.451 \\
p=0.346\end{array}$ \\
\hline $\begin{array}{l}\text { Risk factors } \\
\text { Diabetes } \\
\text { Hypertension } \\
\text { Dyslipidaemia } \\
\text { Atrial fibrillation } \\
\text { Past history of stroke or TIA } \\
\text { Smoking }\end{array}$ & $\begin{array}{c}44(37.9) \\
59(50.9) \\
49(42.2) \\
05(4.3) \\
44(37.9) \\
66(56.9)\end{array}$ & $\begin{array}{c}53(46.9) \\
76(67.3) \\
43(38.1) \\
10(8.8) \\
30(26.5) \\
02(1.8)\end{array}$ & $\begin{array}{c}97(42.4) \\
135(58.9) \\
92(40.2) \\
15(6.5) \\
74(32.3) \\
68(29.7)\end{array}$ & $\begin{array}{l}p=0.17 \\
p=0.012 \\
p=0.518 \\
p=0.171 \\
p=0.066 \\
p<0.001\end{array}$ \\
\hline $\begin{array}{l}\text { Type of stroke } \\
\text { Lacunar stroke } \\
\text { Non-lacunar stroke }\end{array}$ & $\begin{array}{l}73(62.9) \\
43(37.1)\end{array}$ & $\begin{array}{l}61(54.9) \\
52(46.0)\end{array}$ & $\begin{array}{c}134(58.5) \\
95(41.5)\end{array}$ & $p=0.169$ \\
\hline $\begin{array}{l}\text { Severity of stroke* } \\
\text { NIHSS, mean (SD) } \\
\text { GCS, mean (SD) }\end{array}$ & $\begin{array}{l}6.01(4.87) \\
14.43(1.8)\end{array}$ & $\begin{array}{c}5.61(4.12) \\
13.7(2.6)\end{array}$ & $\begin{array}{l}5.82(4.52) \\
14.09(2.3)\end{array}$ & $\begin{array}{c}p=0.53 \\
p=0.019\end{array}$ \\
\hline $\begin{array}{l}\text { Disability on discharge* } \\
\text { Barthel Index } \\
\text { MRS Index }\end{array}$ & $\begin{array}{c}11.28(6.2) \\
3.51(1.5)\end{array}$ & $\begin{array}{c}9.39(6.1) \\
3.89(1.43)\end{array}$ & $\begin{array}{c}10.34(6.2) \\
3.7(1.5)\end{array}$ & $\begin{array}{l}p=0.023 \\
p=0.052\end{array}$ \\
\hline
\end{tabular}

* These variables are given as mean (SD) 
Table 2. Vascular risk factors in and non-LAC stroke (univariate and multivariate logistic regression)

\begin{tabular}{|c|c|c|c|c|c|c|}
\hline \multirow[t]{2}{*}{ Risk factor } & \multirow{2}{*}{$\begin{array}{l}\text { LAC } \\
n(\%)\end{array}$} & \multirow{2}{*}{$\begin{array}{l}\text { Non-LAC } \\
n(\%)\end{array}$} & \multicolumn{2}{|c|}{ Univariate analysis } & \multicolumn{2}{|c|}{ Multivariate analysis } \\
\hline & & & OR $(95 \% C I)$ & $p$ value & OR $(95 \% C I)$ & $p$ value \\
\hline Average age & $66.1+/-11.96$ & $65.1+/-12.65$ & $1.005(0.98-1.03)$ & 0.644 & & \\
\hline Male sex & $75(57.7)$ & $41(41.4)$ & $1.93(1.14-3.28)$ & 0.015 & $1.90(1.09-3.31)^{\mathrm{a}}$ & 0.023 \\
\hline $\mathrm{DM}$ & $60(46.2)$ & $37(37.4)$ & $1.44(0.84-2.45)$ & 0.183 & & \\
\hline $\mathrm{HT}$ & $80(61.5)$ & $55(55.5)$ & $1.28(0.75-2.18)$ & 0.362 & & \\
\hline Dyslipidaemia & $60(46.2)$ & 32 (32.3) & $1.79(1.04-3.09)$ & 0.034 & $1.58(0.87-2.90)^{\mathrm{b}}$ & 0.125 \\
\hline Smoking & $43(33.1)$ & $25(25.3)$ & $1.46(0.82-2.62)$ & 0.199 & & \\
\hline IHD & $27(20.8)$ & $21(21.2)$ & $0.97(0.51-1.85)$ & 0.935 & & \\
\hline Past history of TIA/ stroke & $40(30.7)$ & $34(34.3)$ & $0.85(0.48-1.48)$ & 0.567 & & \\
\hline Atrial fibrillation & $04(3.08)$ & $11(10.1)$ & $0.26(0.08-0.85)$ & 0.026 & $0.30(0.09-0.99)^{c}$ & 0.049 \\
\hline
\end{tabular}

a Adjusted for DM, HT, Dyslipidaemia and presence of atrial fibrillation

b Adjusted for DM, HT, male sex and presence of atrial fibrillation

c Adjusted for male sex, dyslipidaemia

fibrillation was significantly less among patients with LAC than non-LAC infarcts.

Stroke severity was assessed using NIHSS and GCS. Table 3 compares the stroke severity, disability and mortality during hospital stay and within 28 days of discharge.

Disability assessed by MRS and Barthel index has improved following discharge in both stroke subtypes. However, disability was significantly less in the LAC group. Stroke recurrence and re-hospitalisation could not be correlated due to the low number of events and short follow up. Deaths during hospital stay and at 28 days were less in LAC infarcts compared to non-LAC.

\section{Table 3. Stroke severity, death and disability of LAC versus non-LAC stroke determined by chi-square and t-tests}

\begin{tabular}{|c|c|c|c|}
\hline Outcome variable & $\begin{array}{l}L A C \\
n=130\end{array}$ & $\begin{array}{l}\text { Non-LAC } \\
n=99\end{array}$ & $p$ value \\
\hline \multicolumn{4}{|l|}{ Stroke severity* } \\
\hline NIHSS & $5.34(3.93)$ & $6.6(5.29)$ & 0.053 \\
\hline GCS & $14.66(1.2)$ & $13.34(3.0)$ & $<0.001$ \\
\hline \multicolumn{4}{|c|}{ Disability on discharge* } \\
\hline MRS & $3.27(1.4)$ & $4.26(1.4)$ & $<0.001$ \\
\hline Barthel Index & $11.98(5.3)$ & $8.05(6.6)$ & $<0.001$ \\
\hline \multicolumn{4}{|l|}{ Disability at 28 days* } \\
\hline MRS & $2.38(1.7)$ & 3.62 (1.9) & $<0.001$ \\
\hline Barthel index & $16.06(4.8)$ & $13.8(5.8)$ & 0.007 \\
\hline \multicolumn{4}{|l|}{ Mortality } \\
\hline \multicolumn{4}{|l|}{ Death during } \\
\hline Death within 28 days & s $\quad 07(5.5)$ & $22(25.0)$ & $<0.001$ \\
\hline
\end{tabular}

* These variables are given as mean (SD) and analyzed by t-test. Other variable was analyzed using chi-square test

\section{Discussion}

This is a study comparing risk factors and outcome of ischaemic stroke subtypes in Sri Lanka. LAC stroke comprised $56.8 \%$ of ischaemic stroke included in our hospital based stroke registry. This finding is comparable to data from other Asian countries such as Japan and China $[1,13]$. Studies on stroke in European and North American countries show a higher non-LAC burden [1, 14]. Small vessel disease appears to be commoner in the Asian region than in the West.

Interestingly, males were twice more likely to develop LAC than non-LAC stroke while females had higher number of non-LAC but the difference was not significant. Previous studies do not report a gender difference in developing different stroke subtypes. However, one study reported that males had more non-LAC than LAC in their population based survey conducted in China [1]. Our study showed that males had more LAC stroke despite having a lower incidence of diabetes and hypertension than females. As a result, males had a lower disability (MRS, Barthel Index) and less severe stroke in our study. This finding suggests that vascular disease in Sri Lankan females was different. Vascular risk factors and atrial fibrillation were commoner in females than males in our study.

Risk factors were not different in the LAC and nonLAC groups. Contrary to studies demonstrating an increased incidence of hypertension, diabetes, dyslipidaemia, smoking in Caucasians and Asians with LAC, our study did not reveal a significant excess of these risk factors [1,5-7]. But a later systematic meta-analysis, reported that except for a marginal excess of hypertension in LAC, none of the other risk factors were predictive of either stroke subtype [11]. Most of the earlier studies have 
included aetiological risk factors in the definition of LAC or non-LAC leading to a selection bias [11]. The presence of chronic atrial fibrillation predisposes to non-LAC as seen in all previous studies as well as ours. The reasons for LAC being commoner among Asians are unknown. Several studies have evaluated the possibility of endothelial dysfunction, abnormal coagulation in LAC strokes but findings were not consistent (15). Identification of arterial pathology in LAC is important and could provide targets for preventive therapy in the future.

Our study evaluated the severity and the residual disability of each stroke subtype. We found that LAC group had less severe stroke and a significantly lesser disability than non-LAC on discharge. This difference persisted at 28 days and LAC group had a better overall outcome. Deaths were significantly less in the LAC group during the hospital stay and at 28 days after discharge. These findings are not surprising. Most previous studies reported similar results and this difference could be related to the size of the infarct. However, analysis of the long term outcome in these studies showed that mortality and stroke recurrence appear to be similar after the first 1-2 years. Follow up of our study cohort would help identify whether this is the same for Sri Lankans.

This was a hospital based study conducted in a tertiary care hospital in Colombo. But patients are admitted directly from the community in addition to referrals and transfers from smaller hospitals. Our sample included patients from different social backgrounds and ethnicities and an adequate sample to allow inferences. Therefore our findings can be generalized to other parts of Sri Lanka.

LAC stroke appears to be commoner than non-LAC in Sri Lanka. Males were more likely to develop LAC. Diabetes, hypertension, smoking, dyslipidaemia or advanced age did not differ among subtypes of stroke but atrial fibrillation predisposed to non-LAC. Stroke severity and disability were more and early survival was better in the LAC than non-LAC group.

\section{Acknowledgements}

Authors acknowledge the permission of the hospital director to carry out the study.

\section{Conflicts of interests}

There are no conflicts of interest.

\section{References}

1. Fang XH, Wang WH, Zhang XQ, et al. Incidence and survival of symptomatic lacunar infarction in a Beijing population: a 6-year prospective study. Eur J Neurol 2012; 19: 1114-20.

2. Medical Statistics Unit, Ministry of Health. Annual Health Bulletin 2012; 27. http://www.health.gov.lk/ AnnualHealthBulletin.htm. (Accessed on $26^{\text {th }}$ May 2014)

3. Wijesundara WRUAS, Weeratunga LL, Wijetunga WMUA, et al. Risk factors and prevalence of non-fatal stroke in Sri Lanka - a community based study. Annual Research Symposium 2012, University of Colombo; 260-61.

4. Fisher CM. Lacunes: small, deep cerebral infarcts. Neurology 1965; 15: 774-84.

5. Wu B, Lin S, Hao Z, et al. Proportion, risk factors and outcome of lacunar infarction: a hospital-based study in a Chinese population. Cerebrovasc Dis 2010; 29: 181-7. doi: $10.1159 / 000267277$.

6. Sacco SE, Whisnant JP, Broderick JP, et al. Epidemiological characteristics of lacunar infarcts in a population. Stroke 1991; 22: 1236-41.

7. Ohira T, Shahar E, Chambless LE, et al. Risk factors for ischaemic stroke subtypes: The Atherosclerosis Risk in Communities Study. Stroke 2006; 37: 2493-8.

8. Sacco S, Marini C, Totaro R, et al. A population-based study of the incidence and prognosis of lacunar stroke. Neurology 2006; 66: 1335-8.

9. Hong SH, Park HM, Ahn JY, et al. Ace I/D polymorphism in Korean patients with ischemic stroke and silent brain infarction. Acta Neurol Scand 2008; 117: 244-9.

10. Gunatilake SB, Jayasekera BA, Premawardene AP. Stroke subtypes in Sri Lanka - a hospital based study. Ceylon Med J 2001; 46: 19-20.

11. Jackson C, Sudlow C. Comparing risks of death and recurrent vascular events between lacunar and non-lacunar infarction. Brain 2005; 128: 2507-17.

12. Adams HP, Bendixen BH, Kappelle LJ, et al. Classification of subtype of acute ischaemic stroke. Definitions for use in a multicenter clinical trial. TOAST. Trial of Org 10172 in Acute Stroke Treatment. Stroke 1993; 24: 35-41.

13. Kubo M, Kiyohara Y, Ninomiya T, et al. Decreasing incidence of lacunar vs other types of cerebral infarction in a Japanese population. Neurology 2006; 66: 1539-44.

14. Eriksson S.E, Olsson J.E. Survival and Recurrent Strokes in Patients with Different Subtypes of Stroke: A Fourteen-Year Follow-Up Study. Cerebrovasc Dis 2001; 12: $171-80$

15. Wiseman S, Marlborough F, Doubal F, Webb D J, Wardlaw J. Blood Markers of coagulation, Fibrinolysis, Endothelial Dysfunction and Inflammation in lacunar stroke versus nonlacunar Stroke and non-Stroke: Systematic Review and Meta-Analysis. Cerebrovasc Dis 2014; 37: 64-75. 